https://doi.org/10.48009/2_iis_2005_50-56

\title{
ELECTRONIC SUPPLY CHAIN COOPERATION: CONSIDERING THREE CAPABILITIES OF INTERORGANIZATIONAL INFORMATION TECHNOLOGY INFRASTRUCTURE
}

\author{
Haiwook Choi, Morehead State University, h.choi@moreheadstate.edu \\ Hae-Yeon Choi, Savannah State University, choih@savstate.edu
}

\begin{abstract}
The use of interorganizational IT infrastructure such as Internet, EDI, ebXML, Web Services, and IOSs between firms in supply chain has given rise to new form of interfirm relationship, called electronic cooperation. Based on studies in IT infrastructure framework, interorganizational relationships, and marketing channels, this study draws a research model describing: the relationships between three capabilities of interorganizational IT infrastructure (technological capability, structural capability, and informational capability) and the relationships between structural and informational capability and electronic cooperation. The research model was tested based on the data collected from IT managers in automobile and retail industries and the results confirm the relationships in the model.
\end{abstract}

Keywords: Interorganizational information technology infrastructure, Interfirm relationships, Electronic cooperation, Supply chain.

\section{INTRODUCTION}

The use of Internet, electronic data exchange (EDI), ebXML, Web Services, and interorganizational information systems (IOSs) is now becoming an increasingly common way of doing business among various organizations in supply chain. Moreover, there are increasing numbers of studies that view these technologies as interorganizational IT infrastructure $[4,5]$. Interorganizational IT infrastructure is defined as a set of IT resources shared among organizations, which include communication networks, hardware, IT applications, standards for data transmission, and human IT skills, knowledge, and experiences [5]. Interorganizational IT infrastructure provides a common IT foundation for interfirm businesses and processes. It also offers firms shared IT services that facilitate the exchange of information, goods, and services. Studies in both organization and information systems (IS) areas found that there has recently been a move to cooperation between firms and interorganizational IT infrastructure has been a driving force behind this trend [2, 4]. This IT-guided cooperation is called electronic cooperation [3].

In this study, we are concerned with electronic cooperation achieved through the use of interorganizational IT infrastructure in supply chain context. Since there has been limited number of empirical studies delineating the role of IT in the (re)structuring cooperative interfirm relationships [6], we will empirically examine the role of three IT capabilities of interorganizational IT infrastructure on electronic cooperation. More specifically, we will test the relationships among three capabilities of interorganizational IT infrastructure and the contributions of two capabilities on electronic cooperation. 


\section{RESEARCH FRAMEWORK}

\section{Interorganizational IT Infrastructure Capabilities and Electronic Cooperation}

The primary role of interorganizational IT infrastructure is to provide shared IT capabilities facilitating information sharing, coordinating business processes across organizations, and finally establishing cross-organizational integration [11]. Bensaou and Venkatraman [4] and Choi [7] identify the following three IT capabilities of interorganizational IT infrastructure: technological, structural, and informational capability. These capabilities refer to IT functionality provided, electronic linkages established, and richness of information exchange made through interorganizational IT infrastructure, respectively. They are consistent to the three IT infrastructure capabilities addressed by Broadbent, et al. [5]: IT services, reach, and range.

Cooperation, by definition, requires joint efforts or actions taken by independent firms to achieve mutual outcomes or singular outcomes [1]. Cooperative structure is enabled by highly customized components or integrated subsystems and thus requires high levels of interdependence between organizations. Likewise, electronic cooperation is described as a tightly coupled interfirm relationship achieved by IT [24]. This IT-induced cooperation lays the middle between the electronic markets (transaction-oriented markets such as stock exchanges) and electronic hierarchies (centrally directed interactions within a single firm) [8] and involves explicit coordination through high relation-specific investment and information processing capabilities [4, 12]. Electronic cooperation is measured as the level of an organization's dedication to its partners [24]. Transaction volume, frequency of contact, and degree of joint decision-making are most frequently used measures as objective indicators of electronic cooperation in transaction cost economics, strategic management, and marketing studies [4, 12, 19].

\section{Technological Capability}

Technological capability represents provision of shared IT functionality on which interfirm IT applications are implemented and used [5]. The extent to which interorganizational IT infrastructure provide shared IT functionality, such as an integrated telecommunication network, task/team support technologies (e.g., groupware and discussion databases), information-rich media, and united customer database, determines the nature and scope of technological capability. For example, a common or third-party IT infrastructure such as Value Added Network (VAN) is likely to offer more extensive technological capability, while a Private Proprietary Network (PPN) provide more selective IT functionality for EDI applications.

Based on the extensiveness and selectiveness of IT functionality, technological capability determines the intensity and scope of IT use among partnering firms for information exchange and electronic interactions [4]. The greater intensity and scope of IT use tend to make partnering firms build relation-specific workflows, processes, and human skills [12, 22]. Moreover, the intensity and scope of IT use delineate the "reach" of partnering firms, which is described as the locations and degree of electronic linkages supply chain partners can reach [15]. Thus, more extensive technological capability is likely to support partnering firms to establish multiple and more intensive interaction structures which link their various functional areas and even customers or competitors. In addition, the greater intensity and scope of IT use make partnering firms improve information access and information processing capabilities [23, 18]. Thus, technological capability also supports partnering firms to exchange a variety of information more completely and accurately. 


\title{
Hypothesis 1a: More extensive technological capability of interorganizational IT
} infrastructure will lead to more intensive structural capability.

\author{
Hypothesis 1b: More extensive technological capability of interorganizational IT \\ infrastructure will lead to richer informational capability.
}

\section{Structural Capability}

The structural capability determines the interaction patterns or structures established among supply chain partners. Interaction structures involves rules and procedures, direct contacts, task forces, and liaison personnel supporting information exchange between firms and thus are related to interfirm information processing capabilities [10, 20]. These structures have different capacity for interfirm coordination, especially due to their contributions to the nature and scope of electronic linkages established between firms. In general, structural capability determines the interaction governance mechanisms which carry out organizational duties, through directing the flow of information, managing the depth, breadth, formality, and centrality of interactions, and capturing the complex and dynamic interchange between partners [19]. In organization studies, the structure of interfirm interactions have been widely studied as important factors that influence interfirm relationships [23] and as direct correspondence to the nature of electronic cooperation [16]. Indeed, successful partnerships exhibit effective interaction channels. Information processing view of organizations sees information exchange as a central phenomenon in organizations, and has contributed greatly to the understanding of information exchange behaviors that affect the development and quality of interfirm relationships [18].

Daft and Lengel [10] state that structural design can provide information of suitable richness to reduce equivocality as well as offer sufficient data to reduce uncertainty. More intense and diverse interaction structure between supply chain partners increases the amount and diversity of information exchanged between firms in the supply chain [16]. Through such interaction channels, partnering firms will be able to handle more relation-specific information such as proprietary data formats which do not directly match to the industry- established document standards. In this way structural capability also increase the quality of information exchange and information representation [17].

\section{Hypothesis 2a: More intensive structural capability of interorganizational IT} infrastructure will lead to richer information capability.

\section{Hypothesis 2b: More intensive structural capability of interorganizational IT infrastructure will lead to higher electronic cooperation.}

\section{Informational Capability}

Informational capability of interorganizational IT infrastructure refers to richness of information exchanged between organizations in that it determines the diversity of information exchange and the quality of information exchange [7,13]. Informational capability enables partnering firms to handle a number of distinctive information types (e.g., a variety of data types and business transaction formats) and helps them to manage diversified information issues that occurred in exchanging a broad range of information. Without support for diversity of information exchange, organizations will confront internal information conversion issues, which can complicate and overwhelm their business transaction processes [19]. Therefore, information 
diversity supports free and frequent communications with minimum obstacles and consequently facilitates better cooperation between partnering firms.

In general, interfirm relationships loose efficiency when transactions involve highly embedded organizational and technical resources and capabilities, conditions which require high quality of information exchange (e.g., credibility of information exchange activities) [21]. Poor quality of information exchange often causes incomplete and inaccurate information exchanged and leads to feeling of frustration [10], which leads firms to be reluctant to contact their partners. Information exchange quality is expected to reduce or eliminate misunderstandings that may arise on account of errors in information exchange due to inaccurate, incomplete, and late information transmission of organizations' intentions. Especially in interorganizational relationships area, information quality is considered as critical signal for future intentions and interpreted as an overt manifestation of more subtle phenomena such as trust and commitment [19]. Therefore, it reduces the extent of conflicts in organizations and improves electronic cooperation between partnering.

\section{Hypothesis 3: Richer informational capability of interorganizational IT infrastructure will lead to higher electronic cooperation.}

\section{RESULTS OF SEM ANALYSIS}

To test the research model, we collected data through a self-administered questionnaire from IT managers in manufacturing and retailing industries and used structural equation modeling (SEM) for data analysis. The unit of analysis for this study is a dyad, dyadic relationship between several large buyers and their respective suppliers.

The test of hypotheses consists of two steps: testing measurement and research model [14]. The results of measurement model shown in Table 1 indicate that the residual matrix contains no values significantly different from zero supporting the adequacy of the model and that the construct reliabilities are sufficiently high- 0.86 for technological capability, 0.90 for structural capability, 0.81 for informational capability, 0.88 for electronic cooperation.

Table 1. Parameter Estimates and Reliability Statistics of Constructs

\begin{tabular}{|c|c|c|c|c|}
\hline Construct & Parameter & ML Estimate & t-Value** & Reliability \\
\hline & TC1 & 0.79 & & \\
Technological & TC2 & 0.95 & 9.79 & \\
Capability (TC) & TC3 & 0.70 & 7.86 & 0.86 \\
\hline & SC1 & 0.81 & & \\
Structural & SC2 & 0.89 & 9.15 & 0.90 \\
Capability (SC) & SC4 & 0.68 & 7.23 & \\
& SC5 & 0.86 & 9.78 & \\
& SC6 & 0.74 & 8.00 & \\
Informational & IC1 & 0.94 & 8.64 & \\
Capability (IC) & IC2 & 0.70 & 7.02 & 0.81 \\
\hline Electronic & EC1 & 0.94 & & \\
Cooperation (EC) & EC2 & 0.82 & 9.32 & \\
\hline
\end{tabular}

The first item ML estimate in each construct is fixed at 1.00 and does not have a t-value.

** All t-values are significant at $\mathrm{p}<0.01$.

Figure 1 and Table 2 show the hypothesized model and its path and fit indices. The observed $\chi^{2}$ for the hypothesized model is $71.27(\mathrm{df}=41, \mathrm{p}=0.001)$. The GFI, AGFI, NFI, CFI, 
and RMSEA are $0.92,0.86,0.94,0.99$, and 0.042 respectively. Adjusting for degrees of freedom, the normed value of $\chi^{2}$ is 1.74 . Both the normed value of $\chi^{2}$ and absolute fit (i.e., GFI, AGFI, RMSEA) and comparative fit indices (i.e., NFI, CFI) indicate that the hypothesized model is a good-fitting model. As shown in Table 2, most path coefficients are of high magnitude and exhibit high t-values. These values range from 0.25 to 0.90 . The $t$-value indicates that all path coefficients are significant at $p=0.05$. Furthermore, the coefficient of determination for structural equations is 0.96 for the model, indicating that $96 \%$ of variance of electronic cooperation is explained by indicators.

Figure 1. Hypothesized Model Showing Path ${ }^{\mathrm{a}}$

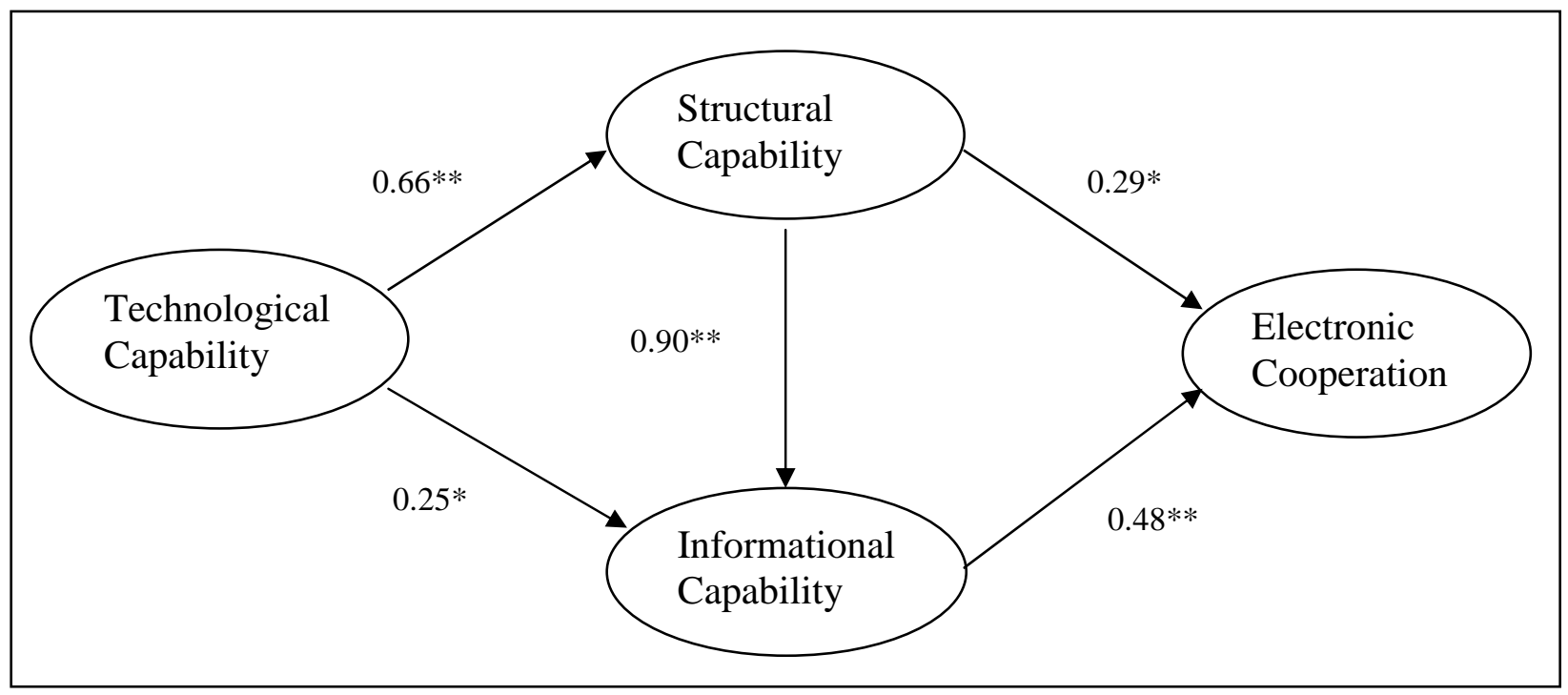

${ }^{\text {a }}$ The $\lambda$ s and $\delta$ s are omitted for schematic simplicity

Table 2. Path and Fit Indices for Hypothesized Model

\begin{tabular}{|l|c|c|}
\hline \multicolumn{1}{|c|}{ Path } & Coefficient $(\beta)$ & $\mathrm{t}-$ Value \\
\hline Technological Capability -> Structural Capability & 0.66 & $6.24^{* *}$ \\
Technological Capability -> Informational Capability & 0.25 & $2.15^{*}$ \\
Structural Capability -> Informational Capability & 0.90 & $6.61^{* *}$ \\
Structural Capability -> Electronic Cooperation & 0.29 & $2.09^{*}$ \\
Informational Capability -> Electronic Cooperation & 0.48 & $3.16^{* *}$ \\
\hline Measures of Model Fit & & \\
$\chi^{2}=71.27(\mathrm{df}=41 ; \mathrm{p}=0.002) ; \chi^{2} / \mathrm{df}=1.74$ & & \\
GFI $=0.92 ;$ AGFI $=0.86 ; \mathrm{NFI}=0.94 ; \mathrm{CFI}=0.99 ;$ RMSEA $=0.042$ & \\
\hline
\end{tabular}

*significant at $\mathrm{p}<0.05$

$* *$ significant at $\mathrm{p}<0.01$

Cohen [9] recommends the interpretation of size effect of path coefficient $(\beta)$ in the social science. Standardized path coefficients with absolute values less than 0.10 may indicate a "small" effect; values around 0.30 a "medium" one; and "large" effects may be suggested by coefficients with absolute values of 0.50 or more. According to his recommendation, we argue that all constructs in the model show moderate or strong association. More specifically, technological capability has strong and moderate association with technological and informational capabilities $(\beta=0.66, \beta=0.25)$, respectively. Structural capability shows strong association with information 
capability and moderate association with electronic cooperation $(\beta=0.90, \beta=0.29)$. Information capability displays strong association with electronic cooperation $(\beta=0.48)$. Furthermore, the $\mathrm{t}$-values of these constructs are significant at $\mathrm{p}<0.05$ or $\mathrm{p}<0.01$. Therefore, $\mathrm{H}_{1 \mathrm{a}}, \mathrm{H}_{1 \mathrm{~b}}, \mathrm{H}_{2 \mathrm{a}}, \mathrm{H}_{2 \mathrm{~b}}$, and $\mathrm{H}_{3}$ were supported.

\section{DISCUSSION AND CONCLUSIONS}

This paper tests the relationships among three capabilities of interorganizational IT infrastructure and the contributions of the two on electronic cooperation. Our findings provide a greater understanding of the roles of interorganizational IT infrastructure on cooperative interfirm relationships in supply chain. First, our findings indicate that technological capability has impacts on electronic cooperation through enabling partnering firms to build intensive interaction structures and to exert rich information exchange activities, instead of having direct relation to electronic cooperation. This finding is consistent to the research in IS success. The IS success studies describe that IT capability determines organizational IT use and in turn, IT use affects organizational performance.

Second, the interaction structures formed through structural capability have impact on electronic cooperation directly and through information capability. The findings also confirm the existence of the relationships between structural governance and cooperative relationships in information systems, organization, and marketing areas [19, 23]. As structural capability increases the amount of information exchanged between partners, the equivocality and uncertainty accompanied to interfirm relationships are reduced [10] and the opportunity for taking cooperative and coordinated actions in the relationships is also enhanced.

We found interesting results in relation to the path to electronic cooperation. The strong path of technological capability $\rightarrow$ structural capability $\rightarrow$ informational capability $\rightarrow$ electronic cooperation is our potentially most influential finding. This finding indicates that the role of interorganizational IT infrastructure on interfirm relationship will be better achieved by supporting a variety of interaction channels for aligning business processes, communicating business strategies, building trust, and sharing information between supply chain partners. This finding may give us a guideline for further research. Instead of looking for a direct relationship of structural capability to cooperation, the influences of structural capability on process integration, trust, and information sharing behavior and procedures which have been discussed as critical factors of cooperation in the literature will be worthwhile to investigate.

\section{REFERENCES}

1. Anderson, J. C., \& Narus, J. A. (1990). A Model of the Distributor-Manufacturer Working Relationships, Journal of Marketing, (54), 42-58.

2. Bakos, J. Y. \& Nault, B. R. (1997). Ownership and Investment in Electronic Networks, Information Systems Research, 8(4), 321-340.

3. Bensaou, M. (1997). Interorganizational Cooperation: The Role of Information Technology: An Empirical Comparison of U.S. and Japanese Supplier Relations, Information Systems Research, 8(2), 107-124.

4. Bensaou, M. \& Venkatraman, N. (1995). Configurations of Interorganizational Relationships: A Comparison between U.S. and Japanese Automakers, Management Science, 41(9), 1471-1492. 
5. Broadbent, M., Weill, P., \& St. Clair, D. (1999). The Implications of Information Technology Infrastructure for Business Process Redesign, MIS Quarterly, 23(2), 159-182.

6. Christiaanse, E. \& Venkatraman, N. (2002). Beyond SABRE: An Empirical Test of Expertise Exploitation in Electronic Channels, MIS Quarterly, 26(1), 15-38.

7. Choi, H. (2002). The Effects of Interorganizational Information Systems Infrastructure (IOSI) on Electronic Cooperation: An Investigation of the "Move to the Middle", Doctoral Dissertation, Southern Illinois University.

8. Clemons, E. K., Reddi, S. P., \& Row, M. (1993). The Impact of Information Technology on the Organization of Economic Activity: The "Move to the Middle" Hypothesis, Journal of Management Information Systems, 19(2), 9-35.

9. Cohen, J. (1988). Statistical Power Analysis for the Behavioral Sciences $\left(2^{\text {nd }}\right.$ ed.). New York: Academic Press.

10. Daft, R. L. \& Lengal, R. H. (1986). Organizational Information Requirements, Media Richness and Structural Design, Management Science, (32), 554-571.

11. Darton, G., \& Giacoletto, S. (1992). Information and IT Infrastructures. In Information in the Enterprise: It's More Than Technology. Salem, MS: Digital Press.

12. Dyer, J. (1997). Effective Interfirm Collaboration: How Firms Minimize Transaction Costs and Maximize Transaction Value, Strategic Management Journal, 18(7), 535-556.

13. Evans, P. \& Wurster, T. (1997). Strategy and The New Economics of Information, Harvard Business Review, (September-October), 71-82.

14. Gerbing, D.W., \& Anderson, J.C. (1988). An Updated Paradigm for Scale Development Incorporating Unidimensionality and its Assessment. Journal of Marketing Research, (25), 186-192.

15. Keen, P. G. W. (1991). Shaping the Future: Business Design Through Information Technology. Cambridge, MA: Harvard Business Press.

16. Kenis, P. \& Knoke, D. (2002). How Organizational Field Networks Shape Interorganizational Tie-Formation Rates, Academy of Management Review, 27(2), 275-293.

17. Mohr, J. \& Sohi, R. (1995). Communication Flows in Distribution Channels: Impact on Assessments of Communication Quality and Satisfaction, Journal of Retailing, 71(4), 393-416.

18. Mohr, J. \& Spekman, R. (1994). Characteristics of Partnership Success: Partnership Attributes, Communication Behavior, and Conflict Resolution Techniques, Strategic Management Journal, (15), 135-152.

19. Kumar, N. \& Benbasat, I. (2004). The Effect of Relationship Encoding, Task Type, and Complexity on Information Representation: An Empirical Evaluation of 2D and 3D Line Graphs, MIS Quarterly, 28(2), 255-281.

20. Nadler, D., \& Tushman, M. (1998). Strategic Organization Design. Glenview, IL: Scott, Foresman and Company.

21. Nohria, N. \& Eccles, R. (1992). Networks and Organizations. Boston, MA: Harvard Business School Press.

22. Subramani, M. (2004). How do Suppliers Benefit from Information Technology Use in Supply Chain Relationships? MIS Quarterly, 28(1), 45-73.

23. Vijayasarathy, L. R. \& Robey, D. (1997). The Effect of EDI on Marketing Channel Relationships in Retailing, Information \& Management, 33(2), 73-86.

24. Zaheer, A. \& Venkatraman, N. (1994). Determinants of Electronic Integration in the Insurance Industry: An Empirical Test, Management Science, 40(5), 549-566. 